\title{
Changes in prevalence and perception of complementary and alternative medicine use in Korean inflammatory bowel disease patients: results of an 8-year follow-up
}

\section{survey}

\author{
Sun-Ho Lee ${ }^{1 *}$, Kiju Chang ${ }^{1 *}$, Ki Seok Seo ${ }^{2}$, Yun Kyung Cho ${ }^{1}$, Eun Mi Song ${ }^{1}$, Sung Wook Hwang ${ }^{1}$, Dong-Hoon Yang ${ }^{1}$, \\ Byong Duk Ye ${ }^{1}$, Jeong-Sik Byeon ${ }^{1}$, Seung-Jae Myung ${ }^{1}$, Suk-Kyun Yang ${ }^{1}$, Sang Hyoung Park ${ }^{1}$ \\ Departments of ${ }^{1}$ Gastroenterology and ${ }^{2}$ Surgery, Asan Medical Center, University of Ulsan College of Medicine, Seoul, Korea
}

Background/Aims: The use of complementary and alternative medicine (CAM) is a global phenomenon, including inflammatory bowel disease (IBD) patients. We aimed to assess the change in prevalence and patterns of CAM use, and attitudes towards CAM over an 8-year time interval (2006 vs. 2014) among IBD patients in Korea. Methods: A total of 221 IBD patients $(\mathrm{CD}=142, \mathrm{UC}=79)$ were asked to complete a questionnaire regarding CAM at two time points: at enrollment (2006) and 8 years later $(2014 / 2015)$. Results: The proportion of patients ever using CAM increased significantly from $60.2 \%$ in 2006 to $79.6 \%$ in $2014(P<0.001)$, while the proportion of current CAM users increased slightly (35.7\% to $38.0 \%, P=0.635) ; 21.7 \%$ used CAM consistently at both time points. The proportion of patients who felt CAM was less effective $(P<0.001)$ and more expensive $(P=0.04)$ than conventional treatments increased over time. Also, the proportion among ever CAM users who perceived a positive effect from CAM significantly decreased in 2014 compared to $2006(P=0.004)$. Higher education (adjusted odds ratio [aOR], 2.10), prior side effects to conventional therapies (aOR, 2.23), and prior use of corticosteroids (aOR, 2.51) were associated with CAM use. Interestingly, use of CAM before IBD diagnosis (aOR, 2.73) was significantly associated with consistent CAM use. Conclusions: Although the attitudes toward CAM have become less favorable, the majority of IBD patients have experienced CAM with an overall increase of current CAM users over time. Moreover, more than half of current CAM users used CAM consistently over time. (Intest Res 2020;18:192-199)

Key Words: Complementary and alternative medicine; Inflammatory bowel disease; Colitis, ulcerative; Crohn disease

\section{INTRODUCTION}

Complementary and alternative medicine (CAM) includes practices and products of nonmainstream origin that can be used "together with" or "in place" of conventional medicine. ${ }^{1}$ In

Received September 9, 2019. Revised December 24, 2019

Accepted January 11, 2020

Correspondence to Sang Hyoung Park, Department of Gastroenterology,

Asan Medical Center, University of Ulsan College of Medicine, 88 Olympic-ro

43-gil, Songpa-gu, Seoul 05505, Korea. Tel: +82-2-3010-5768, Fax: +82-2-

476-0824,E-mail: shpark78@amc.seoul.kr

*These authors contributed equally to this study. the past two decades, a number of studies investigated the prevalence and patterns of CAM use worldwide. ${ }^{2}$ CAM use is now regarded as a global phenomenon, with reports showing $21 \%-77 \%$ of IBD patients using CAM at some point after their diagnosis. ${ }^{2-5}$ However, the vast majority of these studies were cross-sectional. Only one study from a population-based cohort of Manitoba investigated the trends of CAM use longitudinally over a period of 4.5 years since $2002 .{ }^{6}$ So far, no study investigated longitudinal data regarding CAM use in the past decade spanning the recent biologic era. Moreover, changes in IBD patients' perceptions and attitudes toward CAM use 
over time has not been addressed.

Therefore, we aimed to perform a prospective longitudinal study to determine the changes in the prevalence of CAM use, patterns of CAM use, and the perception and attitude towards CAM between two different time points (2006 and 2014) in a hospital-based IBD cohort in Korea. We further aimed to determine the risk factors associated with previous or current CAM use and consistent CAM use.

\section{METHODS}

\section{Study Design and Population}

The study was based on responses to a questionnaire which was completed at two different time points spanning an 8-year interval by the study participants. Consecutive patients with a confirmed IBD diagnosis who visited the IBD Center at Asan Medical Center, a tertiary hospital in Seoul, South Korea, during November and December 2006 were enrolled upon agreement to participate in the study. The inclusion criteria were as follows: at least 18 years of age at enrollment; at least 1-year of disease duration; informed consent.

At enrollment, study patients were required to complete a questionnaire regarding socio-demographic information (i.e., age, sex, education level, and average income), previous hospitalization or surgery, previous use of corticosteroids or immunomodulators, and the use of different patterns of CAM at the time of survey, during the previous 12 months, or at any time before or after diagnosis of IBD. Additionally, questions regarding the purpose of CAM use, attitude towards CAM in terms of efficacy, cost, and adverse events, and overall confidence in CAM compared to conventional therapy were in- cluded in the questionnaire. An English version of the questionnaire can be seen in Supplementary Material 1.

The same questionnaire was completed by the initial participants 8 years after enrollment. The second set of questionnaires were completed between June 2014 and April 2015 among those available to participate. The participants who responded to both questionnaires served as the final samples for the analysis of our study.

UC and CD were diagnosed based on the standard clinical, radiological, endoscopic, and histological criteria. ${ }^{7}$ Patient demographics and clinical characteristics of IBD, including the date of diagnosis, Montreal classification, ${ }^{8}$ previous IBD-related surgeries and hospitalizations, and previous medication at enrollment were retrospectively collected from chart review of electronic medical records and from the Asan IBD Registry, which has been prospectively collected and updated since 1997 as described previously. ${ }^{9,10}$

Our study was approved by the Institutional Research Board of Asan Medical Center (IRB No. 2014-0920). Written informed consents were obtained.

\section{Assessment of CAM Use}

CAM was defined in our study according to the National Center for Complementary and Alternative Medicine (NCCAM) in 2005. We used a Korean version of CAM classification which incorporated the 2005 NCCAM classification; CAM was categorized into 7 categories as presented in Table 1. As the NCCAM classification of CAM evolved over time, we reclassified previous categories into CAM products (i.e., herbal therapies, nutrition \& diet, folk/traditional medicine, pharmacological and biological therapies) or CAM services (i.e., manipulative and body-

Table 1. Types of Complementary and Alternative Medicine

\begin{tabular}{|c|c|}
\hline Subgroup & Example \\
\hline Nutrition \& diet & $\begin{array}{l}\text { Royal jelly, chlorella, squalene, chitosan, fish oil, propolis, antler, dry grain food (Sunsik), green vegetable } \\
\text { juice, mugwort, mushroom, ginkgo, fermented soybean, dandelion, megavitamin, fasting, enzyme } \\
\text { preparations }\end{array}$ \\
\hline Manipulative and body-based medicine & $\begin{array}{l}\text { Acupuncture, hand acupuncture, bee sting therapy, cupping, moxibustion, massage, acupressure, } \\
\text { Oigong, lower-body bathing }\end{array}$ \\
\hline Bioelectronics therapies & Magnetic therapy, magnetic field therapy \\
\hline Mind-body medicine & Yoga, meditation, prayer, hypnosis, Tai chi, biofeedback, relaxation therapy \\
\hline Pharmacological and biological therapies & Shark gristle, aroma therapy, neural therapy \\
\hline Others & Charcoal powder, placenta injection, germanium therapy, etc. \\
\hline
\end{tabular}


based medicine, bioelectronics therapies, mind-body medicine) as described in a previous study ${ }^{6}$ for further analyses.

\section{Definitions of Terms and Study Outcomes}

IBD-related hospitalization was defined as at least 48 hours of stay in the hospital due to a flare up of symptoms or other IBDrelated complications. Any admission exclusively for the purpose of a diagnostic work up or other conditions unrelated to IBD were excluded. IBD-related surgery was defined as any colectomy in UC patients or any bowel resection in CD patients; of note, surgery due to dysplasia were excluded from this definition. Ever use of CAM was defined as current or previous use of CAM after IBD diagnosis.

The primary outcome of our study was to determine the changes in the prevalence and patterns of CAM use and attitude towards CAM over time in a hospital-based cohort of IBD patients. The secondary outcome was to determine the risk factors associated with ever use of CAM and consistent use of CAM at both time points.

\section{Statistical Analysis}

Continuous variables were expressed as medians and interquartile ranges, whereas categorical variables were expressed as numbers and percentages. McNemar test was used to compare the paired responses of questionnaires at two different time points. Chi-square test was used to compare the proportion between 2 groups that were considered independent. When comparing the paired results of the questions that had multiple answers, marginal homogeneity test was used. Multivariable logistic regression with backward elimination was used to fit a model for determining risk factors associated with CAM use and to calculate the adjusted odds ratios (aORs) and $95 \%$ CI. A $P$-value of $<0.05$ was considered statistically significant. Statistical analysis was performed with SAS version 9.4 (SAS Institute, Cary, NC, USA).

\section{RESULTS}

\section{Baseline Demographics and Characteristics of the Study Participants}

A total of 369 IBD patients (161 UC, $208 \mathrm{CD}$ ) completed the initial questionnaire in 2006. Among them, 221 patients (79 UC, $142 \mathrm{CD}$ ) completed the follow-up questionnaire during 2014 and 2015. Analyses were conducted on the 221 patients who completed the questionnaires at both time points. The baseline demographics and clinical characteristics of the study
Table 2. Baseline Demographic and Clinical Characteristics of Study Patients

\begin{tabular}{|c|c|c|}
\hline Characteristic & $C D(n=142)$ & UC $(n=79)$ \\
\hline Female sex & $52(36.6)$ & $33(41.8)$ \\
\hline Age at the first survey (yr) & $28.9(24.6-34.5)$ & $46.4(37.1-53.1)$ \\
\hline Age at diagnosis (yr) & $22.8(19.6-28.8)$ & $39.7(30.5-45.5)$ \\
\hline Disease duration (yr) & $5.3(2.8-8.5)$ & $6.9(3.9-10.1)$ \\
\hline \multicolumn{3}{|l|}{ Disease extent at UC diagnosis } \\
\hline Proctitis & NA & $25(31.6)$ \\
\hline Left-sided & NA & $29(36.7)$ \\
\hline Extensive & NA & $19(24.1)$ \\
\hline Missing & NA & $6(7.6)$ \\
\hline \multicolumn{3}{|l|}{ Disease location at CD diagnosis } \\
\hline lleum & $31(21.8)$ & NA \\
\hline Colon & $10(7.0)$ & NA \\
\hline Ileocolon & $101(71.1)$ & NA \\
\hline \multicolumn{3}{|l|}{ Disease behavior at CD diagnosis } \\
\hline Nonstricturing, nonpenetrating & $107(75.4)$ & NA \\
\hline Stricturing & $16(11.3)$ & NA \\
\hline Penetrating & $19(13.4)$ & NA \\
\hline Perianal fistula at CD diagnosis & $55(38.7)$ & NA \\
\hline Hospitalization for IBD & $103(72.5)$ & $29(36.7)$ \\
\hline Major abdominal surgery for IBD & $57(40.1)$ & 0 \\
\hline \multicolumn{3}{|l|}{ Prior use of medications } \\
\hline Corticosteroids & $114(80.3)$ & $58(73.4)$ \\
\hline Thiopurines & $113(79.6)$ & $18(22.8)$ \\
\hline Biologics & $16(11.3)$ & 0 \\
\hline
\end{tabular}

Values are presented as number (\%) or median (interquartile range). NA, not applicable.

patients are shown in Table 2.

\section{Changes in the Prevalence and Patterns of CAM Use Over Time}

The proportion of ever CAM users significantly increased from $60.2 \%(133 / 221)$ in 2006 to $79.6 \%(176 / 221)$ in $2014(P<0.001)$. However, the proportion of current CAM users at both time points ( $35.7 \%$ vs. $38.0 \%, P=0.635)$ were not significantly different. Notably, 48 patients $(21.7 \%)$ used CAM consistently at both time points.

The proportion of patients currently using CAM products only, CAM services only, both CAM products and services, or any CAM products or services at the time of survey was similar between time points. The proportion of current CAM users based on the type of disease was similar across time (2006 to 2014: 
Table 3. Factors Associated with Ever CAM Use in Patients with IBD

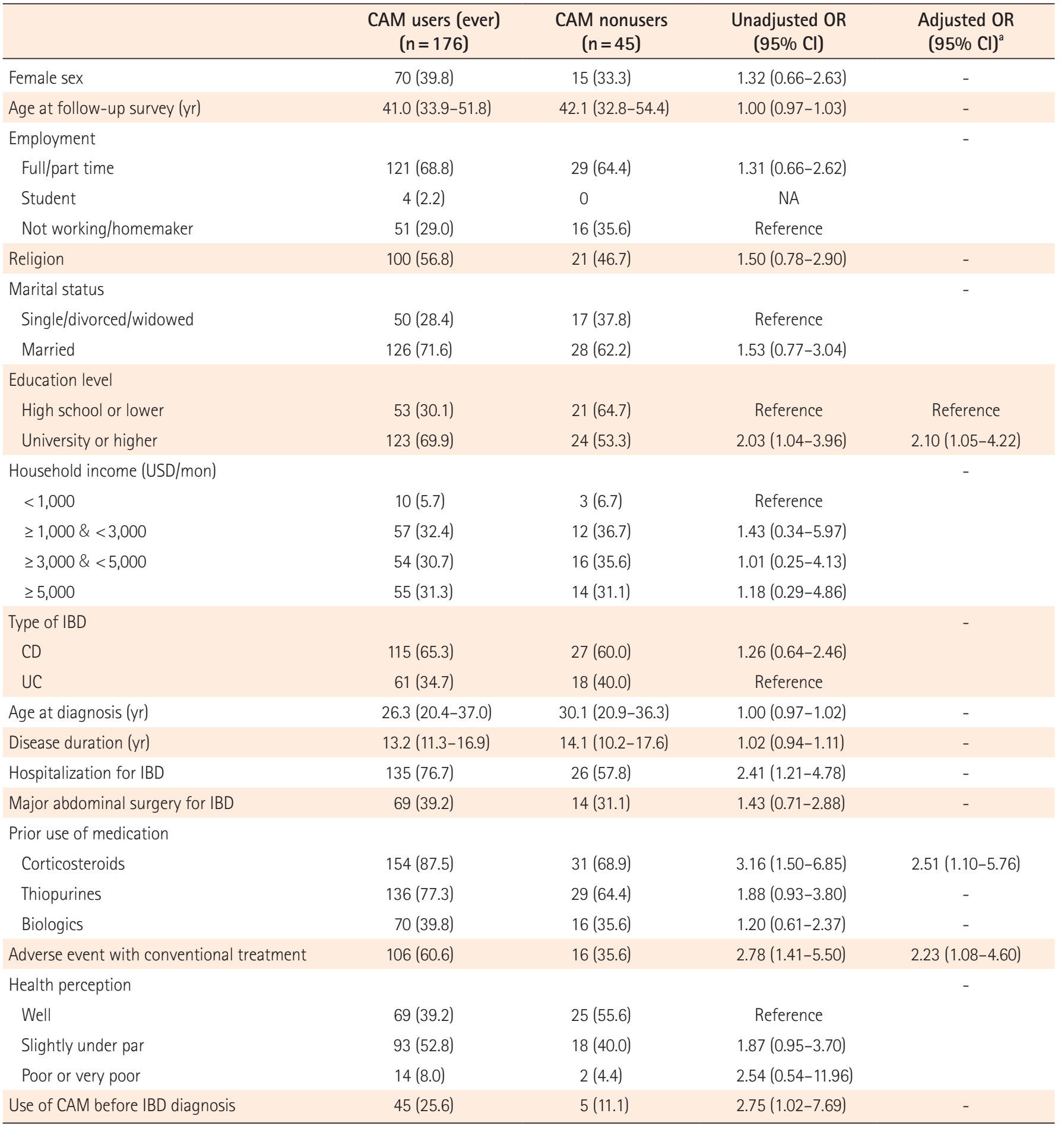

Values are presented as number (\%) or median (interquartile range).

aultivariable analysis using backward elimination strategy was conducted for potentially relevant variables with univariate differences between 2 groups with $P<0.1$.

CAM, complementary and alternative medicine; USD, United States Dollar.

$35.4 \%$ to $45.6 \%$ in UC, $P=0.169 ; 35.9 \%$ to $33.8 \%$ in CD, $P=0.755$ ). The proportion was also similar across time based on sex $(33.1 \%$ to $34.6 \%$ in male, $P=0.878 ; 40 \%$ to $43.5 \%$ in female, $P=0.690$ ).

The most common types of CAM among ever CAM users 
Table 4. Factors Associated with Consistent CAM use in Patients with IBD

\begin{tabular}{|c|c|c|c|c|}
\hline Factor & $\begin{array}{c}\text { Consistent CAM } \\
\text { users }(n=48)\end{array}$ & $\begin{array}{l}\text { Occasional CAM users/ } \\
\text { CAM nonusers }(n=173)\end{array}$ & $\begin{array}{l}\text { Unadjusted OR } \\
\qquad(95 \% \mathrm{Cl})\end{array}$ & $\begin{array}{l}\text { Adjusted OR } \\
(95 \% \mathrm{Cl})^{\mathrm{a}}\end{array}$ \\
\hline Female sex & $22(45.8)$ & $63(36.4)$ & $1.48(0.77-2.82)$ & - \\
\hline Age at follow-up survey, (yr) & $40.7(33.3-51.4)$ & $41.4(33.9-53.3)$ & $1.00(0.97-1.03)$ & - \\
\hline Employment & & & & - \\
\hline Full/part time & $30(62.5)$ & $120(69.4)$ & Reference & \\
\hline Student & 0 & $4(2.3)$ & NA & \\
\hline Not working/homemaker & $18(37.5)$ & $49(28.3)$ & $1.47(0.75-2.88)$ & \\
\hline Religion & $30(62.5)$ & $91(52.6)$ & $1.50(0.78-2.90)$ & - \\
\hline Marital status & & & & - \\
\hline Single/divorced/widowed & $14(29.2)$ & $53(30.6)$ & Reference & \\
\hline Married & $34(70.8)$ & $120(69.4)$ & $1.07(0.53-2.16)$ & \\
\hline Education level & & & & - \\
\hline High school or lower & $13(27.1)$ & $61(35.3)$ & Reference & \\
\hline University or higher & $35(72.9)$ & $112(64.7)$ & $1.47(0.72-2.98)$ & \\
\hline Household income (USD/mon) & & & & - \\
\hline$<1,000$ & $2(4.2)$ & $11(6.4)$ & Reference & \\
\hline$\geq 1,000 \&<3,000$ & $15(31.3)$ & $54(31.2)$ & $1.53(0.31-7.66)$ & \\
\hline$\geq 3,000 \&<5,000$ & $16(33.3)$ & $54(31.2)$ & $1.63(0.33-8.13)$ & \\
\hline$\geq 5,000$ & $15(31.3)$ & $54(31.2)$ & $1.53(0.31-7.66)$ & \\
\hline Type of IBD & & & & - \\
\hline$C D$ & $29(60.4)$ & $113(65.3)$ & $0.81(0.42-1.57)$ & \\
\hline UC & $19(39.6)$ & $60(34.7)$ & Reference & \\
\hline Age at diagnosis (yr) & $25.8(19.5-37.1)$ & $26.9(20.8-36.3)$ & $1.00(0.97-1.02)$ & - \\
\hline Disease duration (yr) & $13.6(11.9-16.7)$ & $13.1(10.9-17.2)$ & $1.02(0.95-1.11)$ & - \\
\hline Hospitalization for IBD & $41(85.4)$ & $120(69.4)$ & $2.59(1.09-6.14)$ & $2.30(0.96-5.54)$ \\
\hline Major abdominal surgery for IBD & $19(39.6)$ & $64(37.0)$ & $1.12(0.58-2.15)$ & - \\
\hline Ever use of medication & & & & - \\
\hline Corticosteroids & $44(91.7)$ & $141(81.5)$ & $2.50(0.84-7.45)$ & \\
\hline Thiopurines & $35(72.9)$ & $130(75.1)$ & $0.89(0.43-1.84)$ & \\
\hline Biologics & $21(43.8)$ & $65(37.6)$ & $1.29(0.68-2.47)$ & \\
\hline Adverse event with conventional treatment & $32(66.7)$ & $90(52.3)$ & $1.82(0.93-3.56)$ & - \\
\hline Health perception & & & & - \\
\hline Well & $19(39.6)$ & $75(43.4)$ & Reference & \\
\hline Slightly under par & $25(52.1)$ & $86(49.7)$ & $1.15(0.59-2.25)$ & \\
\hline Poor or very poor & $4(8.3)$ & $12(6.9)$ & $1.32(0.38-4.54)$ & \\
\hline Use of CAM before IBD diagnosis & $19(39.6)$ & $31(17.9)$ & $3.00(1.50-6.03)$ & $2.73(1.35-5.52)$ \\
\hline
\end{tabular}

Values are presented as number (\%) or median (interquartile range).

${ }^{2}$ Multivariable analysis using backward elimination strategy was conducted for potentially relevant variables with univariate differences between 2 groups with $P<0.1$.

CAM, complementary and alternative medicine; USD, United States Dollar.

based on the follow-up questionnaire in 2014 were herbal therapies $(80.7 \%, 142 / 176)$, nutrition and diet $(67.0 \%, 118 / 176)$, and manipulative and body-based medicine $(27.3 \%, 48 / 176)$. Comparing the types of CAM used within 12 months at each 
time point, there were no significant differences other than a decrease in herbal therapies in 2014 compared to 2006 (58.8\% vs. $75.5 \%, P=0.014)$. Among CAM products, red ginseng (59.7\%), oriental medicine (50.6\%), and fish oil (34.7\%) were most commonly used among ever CAM users based on the follow-up questionnaire in 2014.

\section{Changes in the Perception and Attitude towards CAM Over Time}

Among ever CAM users at both time points (2006, $\mathrm{n}=133$; $2014, \mathrm{n}=176$ ), the proportion of patients who perceived a positive effect after using CAM significantly decreased from $45.9 \%$ in 2006 to $33 \%$ in $2014(P=0.004)$.

Attitude towards CAM use in terms of efficacy and cost as compared with that of conventional treatment has changed significantly at both time points. A significantly higher proportion of patients thought that conventional treatment was more effective in 2014 compared to 2006 ( $62 \%$ vs. $44.8 \%, P<0.001$ ), whereas no significant difference was seen in those who thought CAM was more effective $(P=0.219)$. Also, a significantly higher proportion of patients thought that CAM was more expensive in 2014 compared to 2006 ( $62 \%$ vs. $51.6 \%, P=0.04$ ).

Regarding the purpose of CAM use, in 2006 the majority of CAM users (50.6\%) used CAM to treat IBD, whereas $32.9 \%$ used CAM to improve their general health. In 2014, the proportion decreased to $41.7 \%$ among CAM users who used CAM to treat IBD, whereas the proportion increased to $41.7 \%$ for those aiming to improve their general health; however, the differences in proportions between two time points were not statistically significant $(P=0.3$ and $P=0.3$, respectively).

\section{Risk Factors Associated with CAM Use}

Risk factors associated with ever use of CAM and consistent use of CAM were analyzed, separately. After multivariable analysis, higher education level (aOR, 2.10; 95\% CI, 1.05-4.22), prior use of corticosteroids (aOR, 2.51; 95\% CI, 1.10-5.76), and adverse events with conventional treatment (aOR, 2.23; 95\% CI, 1.08-4.60) were significant risk factors for ever use of CAM. Prior use of CAM before the diagnosis of IBD (aOR, 2.73; 95\% CI, 1.35-5.52) was a significant risk factor for consistent use of CAM in the final multivariable model. The results of univariable and multivariable logistic regression of risk factors associated with ever use of CAM and consistent use of CAM are presented in Tables 3 and 4, respectively.

\section{DISCUSSION}

In the present study, we sought to investigate changes in prevalence and patterns of CAM use as well as the attitudes towards CAM over an 8-year interval in a hospital-based IBD cohort in Korea. One strength of our study was comparing the responses between both time points from the same initial participants to see if their responses on CAM use have changed over time. Moreover, our study identified predictors for CAM use including predictors for consistent use of CAM at both time points. As the landscape of IBD is ever so dynamic in the past decade in terms of new treatment options and algorithms globally, our longitudinal study may be more reflective of how IBD patients are using CAM during the transition period into the biologic era.

To the best of our knowledge, our study is the first to demonstrate the trend of negative attitudes toward CAM use in the recent years regarding its effectiveness and cost. Our results suggest that significantly more patients feel CAM is less effective and more expensive than conventional treatment compared to about a decade ago. Also, we observed a decreased proportion of those who perceived a positive effect toward CAM among CAM users over the years in the current analysis. However, other factors can potentially influence the results. The availability and approval of more effective therapies including biologic agents for IBD patients may have influenced a relatively positive attitude towards conventional treatment recently. ${ }^{11}$ Also, the change of patient environment including the accessibility to medical information from the internet, advent of social media and also activation of on-and-offline IBD communities in the recent years may have influenced our results. Future studies should try to account for the influence of these various factors on the trend of CAM use.

Despite the trend of negative attitude towards CAM across time, the overall proportion of current CAM users slightly increased in 2014 compared to 2006. Also, about $80 \%$ of the responders claimed to have used CAM at least once based on the follow questionnaire in 2014. The prevalence of CAM use in the present study is similar to a previous longitudinal study from Manitoba, where $74 \%$ of responders used CAM at any time point and about $40 \%$ of responders were using CAM at each time point. Interestingly, the proportion of consistent users in our study (21.7\%) was similar but slightly higher than what was seen in the Manitoba study (14\%) at every time point. Although there was a similar trend of CAM use, the 2 studies were quite different in terms of the patterns of CAM use, the 
year of which the study was performed, and the type of cohort (hospital-based vs. population-based).

The patterns and types of CAM show a wide variation between cultures and regions. The most common type of CAM used in our study patients at both time points were herbal therapies (predominantly red ginseng) among ever CAM users. This was consistent with a previous Korean study reporting that a quarter of their IBD patients have used red ginseng. ${ }^{12}$ In Europe, homeopathy and probiotics are common types of $\mathrm{CAM}^{3,4,13-16}$ whereas in Canada, probiotics, fish oil, and massage therapy are commonly used among IBD patients. ${ }^{17}$ In terms of CAM services, the Manitoba study showed that about $31 \%-38 \%$ of IBD patients use CAM services over time (massage and chiropractic practices were most common in Manitoba), ${ }^{6}$ whereas only about $10 \%$ of the current CAM users in our study used CAM service at both time points. These variations may reflect a cultural difference or may be caused by a difference in the study methods or classification of CAM as previously suggested by Zezos and Nguyen. ${ }^{2}$

Our study investigated risk factors associated with CAM use. Higher education level and previous side effects to conventional treatment were previously reported elsewhere. ${ }^{18-21}$ We additionally found prior use of corticosteroids as a significant risk factor in our study. We further looked for risk factors associated with consistent CAM use at both time points; notably, more than half of the current CAM users at each time point used CAM consistently. Interestingly, use of CAM before IBD diagnosis was a significant risk factor. Our results suggest that it is key to ask about the use of CAM even before their diagnosis of IBD, as they may be 2.7 times likely to use CAM consistently over time. Physicians should be aware of these risk factors of CAM use and prepare for proper advice especially in those at risk of using CAM consistently.

Several limitations need to be mentioned. Firstly, a recall bias may have affected our results when answering the questionnaire. Secondly, only about $60 \%$ of the initial participants completed the second questionnaire, of whom a better compliance to medical treatment may be expected. As poor compliance to medical treatment could be associated with increased use of $\mathrm{CAM}^{3}$ the prevalence of CAM in our study may have been underestimated. Thirdly, the generalizability of our results is limited as our study was based on a single referral center. Lastly, we did not account for the change in individuals' disease activity and the currently used IBD medication over time which may have also influenced the pattern of CAM use and attitude towards CAM.
In conclusion, based on the results of an 8-year follow-up survey, although the attitude toward CAM have become less favorable over time, the majority of IBD patients have experienced CAM with an overall increase of current CAM users over time. Moreover, more than a half of current CAM users tend to use CAM consistently at both time points. Physicians should be aware of the high prevalence of CAM use among IBD patients and prepare for proper advice, especially for those who are at risk of consistent CAM use.

\section{FINANCIAL SUPPORT}

The authors received no financial support for the research, authorship, and/or publication of this article.

\section{CONFLICT OF INTEREST}

No potential conflict of interest relevant to this article was reported.

\section{AUTHOR CONTRIBUTION}

Study design: Lee SH, Chang K, Park SH. Acquisition of data: Lee SH, Chang K, Seo KS, Cho YK, Song EM, Hwang SW, Park SH, Yang DH, Byeon JS, Myung SJ, Yang SK, Park SH. Statistical analysis and interpretation of data: Lee SH, Chang K, Park SH, Ye BD. Drafting of manuscript: Lee SH. Critical revision and study supervision: Park SH. All the authors approved the final manuscript.

\section{ORCID}

Lee SH https://orcid.org/0000-0003-0344-0047

Chang K https://orcid.org/0000-0002-1408-9830

Song EM https://orcid.org/0000-0002-2428-1551

Hwang SW https://orcid.org/0000-0002-6981-7575

Yang DH https://orcid.org/0000-0001-7756-2704

Ye BD https://orcid.org/0000-0001-6647-6325

Byeon JS https://orcid.org/0000-0002-9793-6379

Myung SJ https://orcid.org/0000-0003-0585-4016

Yang SK https://orcid.org/0000-0003-2772-2575

Park SH https://orcid.org/0000-0002-5366-5749

\section{SUPPLEMENTARY MATERIAL}

Supplementary materials are available at the Intestinal Re- 
search website (https://www.irjournal.org).

\section{REFERENCES}

1. Complementary, alternative, or integrative health: what's in a name? National Institutes of Health Web site. https://nccih. nih.gov/health/integrative-health. Accessed September 3, 2019.

2. Zezos P, Nguyen GC. Use of complementary and alternative medicine in inflammatory bowel disease around the world. Gastroenterol Clin North Am 2017;46:679-688.

3. Abitbol V, Lahmek P, Buisson A, et al. Impact of complementary and alternative medicine on the quality of life in inflammatory bowel disease: results from a French national survey. Eur J Gastroenterol Hepatol 2014;26:288-294.

4. Bensoussan M, Jovenin N, Garcia B, et al. Complementary and alternative medicine use by patients with inflammatory bowel disease: results from a postal survey. Gastroenterol Clin Biol 2006;30:14-23.

5. Hilsden RJ, Verhoef MJ, Rasmussen H, Porcino A, DeBruyn JC. Use of complementary and alternative medicine by patients with inflammatory bowel disease. Inflamm Bowel Dis 2011;17:655-662

6. Rawsthorne P, Clara I, Graff LA, et al. The Manitoba Inflammatory Bowel Disease Cohort Study: a prospective longitudinal evaluation of the use of complementary and alternative medicine services and products. Gut 2012;61:521-527.

7. Baumgart DC, Sandborn WJ. Inflammatory bowel disease: clinical aspects and established and evolving therapies. Lancet 2007;369:1641-1657.

8. Silverberg MS, Satsangi J, Ahmad T, et al. Toward an integrated clinical, molecular and serological classification of inflammatory bowel disease: report of a Working Party of the 2005 Montreal World Congress of Gastroenterology. Can J Gastroenterol 2005;19 Suppl A:5A-36A.

9. Park SH, Hwang SW, Kwak MS, et al. Long-term outcomes of infliximab treatment in 582 Korean patients with Crohn's disease: a hospital-based cohort study. Dig Dis Sci 2016;61:20602067.

10. Lee HS, Park SH, Yang SK, et al. Long-term prognosis of ulcerative colitis and its temporal change between 1977 and 2013: a hospital-based cohort study from Korea. J Crohns Colitis 2015;9:147-155.

11. Ooi CJ, Hilmi I, Banerjee R, et al. Best practices on immunomodulators and biologic agents for ulcerative colitis and Crohn's disease in Asia. Intest Res 2019;17:285-310.
12. Park DI, Cha JM, Kim HS, et al. Predictive factors of complementary and alternative medicine use for patients with inflammatory bowel disease in Korea. Complement Ther Med 2014;22:87-93.

13. D'Inca R, Garribba AT, Vettorato MG, et al. Use of alternative and complementary therapies by inflammatory bowel disease patients in an Italian tertiary referral centre. Dig Liver Dis 2007;39:524-529.

14. Joos S, Rosemann T, Szecsenyi J, Hahn EG, Willich SN, Brinkhaus B. Use of complementary and alternative medicine in Germany: a survey of patients with inflammatory bowel disease. BMC Complement Altern Med 2006;6:19.

15. Langhorst J, Anthonisen IB, Steder-Neukamm U, et al. Patterns of complementary and alternative medicine (CAM) use in patients with inflammatory bowel disease: perceived stress is a potential indicator for CAM use. Complement Ther Med 2007;15:30-37.

16. Mountifield R, Andrews JM, Mikocka-Walus A, Bampton P. Doctor communication quality and Friends' attitudes influence complementary medicine use in inflammatory bowel disease. World J Gastroenterol 2015;21:3663-3670.

17. Nguyen GC, Croitoru K, Silverberg MS, Steinhart AH, Weizman AV. Use of complementary and alternative medicine for inflammatory bowel disease is associated with worse adherence to conventional therapy: the COMPLIANT Study. Inflamm Bowel Dis 2016;22:1412-1417.

18. Bertomoro P, Renna S, Cottone M, et al. Regional variations in the use of complementary and alternative medicines (CAM) for inflammatory bowel disease patients in Italy: an IG-IBD study. J Crohns Colitis 2010;4:291-300.

19. Koning M, Ailabouni R, Gearry RB, Frampton CM, Barclay ML. Use and predictors of oral complementary and alternative medicine by patients with inflammatory bowel disease: a population-based, case-control study. Inflamm Bowel Dis 2013;19:767-778.

20. Opheim R, Hoivik ML, Solberg IC, Moum B; IBSEN Study Group. Complementary and alternative medicine in patients with inflammatory bowel disease: the results of a populationbased inception cohort study (IBSEN). J Crohns Colitis 2012; 6:345-353.

21. Weizman AV, Ahn E, Thanabalan R, et al. Characterisation of complementary and alternative medicine use and its impact on medication adherence in inflammatory bowel disease. Aliment Pharmacol Ther 2012;35:342-349. 
See "Changes in prevalence and perception of complementary and alternative medicine use in Korean inflammatory bowel disease patients: results of an 8-year follow-up survey" on page 192-199.

Supplementary Material 1. Study Questionnaire (English Version)

Subject Number (

\section{Prospective study of Complementary and Alternative Medicine Use in Inflammatory Bowel Disease Patients}

The current study will be based on responses of this survey which is about the use of complementary and alternative medicine among patients with Ulcerative colitis or Crohn's disease. This survey will be used only as a basis for research related to the patient's disease and survey responses will be kept confidential.

Participation in the survey is your freedom and there is no penalty for your care, even if you do not participate in the survey. However, the results of this survey are valuable data for the establishment of medical policy in Korea, which may be beneficial for patients.

Please read through the material and answer the following questions carefully.

\section{What is complementary and alternative medicine?}

Complementary and alternative medicine (CAM) is different from conventional medicine. It includes all types of treatment that the patient perceives to be effective for their disease, such as auxiliary roles of herbal medicine, dietary supplements, folk remedies and herbal remedies.

There are several types of complementary and alternative medicine as follows:

\begin{tabular}{|l|l|}
\hline Subgroup & \multicolumn{1}{c|}{ Examples } \\
\hline Herbal therapies & Oriental medicine, Red ginseng, Ginseng, Elm leaf, Aloe vera \\
\hline Nutrition \& diet & $\begin{array}{c}\text { Royal jelly, Chlorella, Squalene, Chitosan, Fish oil, Propolis, Antler, Dry grain food (Sunsik), Green } \\
\text { vegetable juice, Mugwort, Mushroom, Ginkgo, Fermented soybean, Dandelion, Megavitamin, Fasting, } \\
\text { Enzyme preparations }\end{array}$ \\
\hline Manipulative and body-based medicine & $\begin{array}{l}\text { Acupuncture, Hand acupuncture, Bee sting therapy, Cupping, Moxibustion, Massage, Acupressure, } \\
\text { Oigong, Lower-body bathing }\end{array}$ \\
\hline Folk/traditional medicine & Gaesoju, Black goat soup, Carp soup, Blood of deer \\
\hline Bioelectronics therapies & Magnetic therapy, Magnetic field therapy \\
\hline Mind-body medicine & Yoga, Meditation, Prayer, Hypnosis, Tai chi, Biofeedback, Relaxation therapy \\
\hline Pharmacological and Biological therapies & Shark gristle, Aroma therapy, Neural therapy \\
\hline Others & Charcoal powder, Placenta injection, Germanium therapy, etc. \\
\hline
\end{tabular}


1. Which of the following is your diagnosis?
(1) Ulcerative colitis
(2) Crohn's disease

2. When was the diagnosis made?

( ) Year ( ) Month

3. What is your biological sex?
(1) Male
(2) Female

4. What is your current age? ( ) years

5. What is your highest level of schooling?
(1) None
(2) Elementary school
(3) Middle school
(4) High school
(5) Completed high school
(6) University
(7) Graduated University or higher

6. Which of the following is your marital status?
(1) Non-married
(2) Married
(3) Divorced or spouse deceased

7. Do you have a religion?
(1) No
(2) Yes (describe specifically: ）

8. Do you have an occupation?
(1) No
(2) Yes (describe specifically: ）
(3) Student
(4) Housewife

9. How much is your monthly income?
(1) None
(2) Less than monthly 1 million won
(3) 1 million $\leq$ monthly income $<2$ million won
(4) 2 million $\leq$ monthly income $<3$ million won
(5) 3 million $\leq$ monthly income $<5$ million won
(6) Monthly 5 million won or more

10. How much is the householder's monthly income? (if you're not the householder.)
(1) None
(2) Less than monthly 1 million won
(3) 1 million $\leq$ monthly income $<2$ million won
(4) 2 million $\leq$ monthly income $<3$ million won
(5) 3 million $\leq$ monthly income $<5$ million won
(6) Monthly 5 million won or more 
11. Have you been hospitalized for Ulcerative colitis or Crohn's disease?
(1) No
(2) 1 time
(3) 2 times
(4) 3 or more times

12. Have you had surgery related to Ulcerative colitis or Crohn's disease?
(1) No
(2) 1 time
(3) 2 times
(4) 3 or more times

13. Have you used systemic steroids (e.g., prednisone) for your Ulcerative colitis or Crohn's disease?
(1) No
(2) Yes

14. Have you used immunomodulators (e.g., azathioprine, purinetone) for your Ulcerative colitis or Crohn's disease?
(1) No
(2) Yes

15. Have you ever experienced side effects from medications prescribed for Ulcerative colitis or Crohn's disease??
(1) No
(2) Yes

16. How many days have you been symptatomatic with Ulcerative colitis or Crohn's disease in the last two weeks?

( ) days

17. How many outpatient visits did you have during the last 12 months due to Ulcerative colitis or Crohn's disease?

( ) times

18. How many days have you been hospitalized in the past 12 months because of Ulcerative colitis or Crohn's disease?

( ) days

19. In the past 12 months, how many days did you have to miss school/work or lie down in hospital/at home because of Ulcerative colitis or Crohn's disease? ( ) days

20. How do you perceive your current health condition?
(1) Well
(2) Slightly under par
(3) Poor
(4) Very poor

21. Have you used complementary and alternative medicine before your diagnosis of Ulcerative colitis or Crohn's disease??
(1) No
(2) Yes

22. Have you used complementary and alternative medicine after your diagnosis of Ulcerative colitis or Crohn's disease?
(1) No
(2) Yes

\section{* If you answered no to 22, you do not have to answer questions 23-37. Only answer questions 38 through 44. Write your answers to questions 23 through 25 in the table below.}

23. Indicate all the complementary and alternative medicine currently in use $(\mathrm{V})$ in the table below.

24. Indicate all the complementary and alternative medicine you have used in the last 12 months (V) in the table below.

25. Indicate all the complementary and alternative medicine that have been used since the onset of Ulcerative colitis or Crohn's disease (V) in the table below. 


\begin{tabular}{|c|c|c|c|c|}
\hline Classification & Types of CAM & $\begin{array}{l}\text { 23. Currently } \\
\text { in use }\end{array}$ & $\begin{array}{l}\text { 24. Used in the } \\
\text { last } 12 \text { months }\end{array}$ & $\begin{array}{l}\text { 25. Used since } \\
\text { onset of disease }\end{array}$ \\
\hline \multirow[t]{5}{*}{ Herbal therapies } & Oriental medicine & & & \\
\hline & Red ginseng & & & \\
\hline & Ginseng & & & \\
\hline & Elm leaf & & & \\
\hline & Aloe vera & & & \\
\hline \multirow{9}{*}{$\begin{array}{l}\text { Manipulative and body-based } \\
\text { medicine }\end{array}$} & Acupuncture & & & \\
\hline & Hand acupuncture & & & \\
\hline & Bee sting therapy & & & \\
\hline & Cupping & & & \\
\hline & Moxibustion & & & \\
\hline & Massage & & & \\
\hline & Acupressure & & & \\
\hline & Qigong & & & \\
\hline & Lower-body bathing & & & \\
\hline \multirow[t]{4}{*}{ Folk/traditional medicine } & Gaesoju & & & \\
\hline & Black goat soup & & & \\
\hline & Carp soup & & & \\
\hline & Blood of deer & & & \\
\hline \multirow[t]{17}{*}{ Nutrition \& diet } & Royal jelly & & & \\
\hline & Chlorella & & & \\
\hline & Squalene & & & \\
\hline & Chitosan & & & \\
\hline & Fish oil (Omega 3) & & & \\
\hline & Propolis & & & \\
\hline & Antler & & & \\
\hline & Dry grain food (Sunsik) & & & \\
\hline & Green vegetable juice & & & \\
\hline & Mugwort & & & \\
\hline & Mushroom & & & \\
\hline & Ginkgo & & & \\
\hline & Fermented soybean & & & \\
\hline & Flowers (Dandelions, etc.) & & & \\
\hline & Megavitamin & & & \\
\hline & Fasting & & & \\
\hline & Enzyme preparations & & & \\
\hline
\end{tabular}


(Continued)

\begin{tabular}{|c|c|c|c|c|}
\hline Classification & Types of CAM & $\begin{array}{l}\text { 23. Currently } \\
\text { in use }\end{array}$ & $\begin{array}{l}\text { 24. Used in the } \\
\text { last } 12 \text { months }\end{array}$ & $\begin{array}{l}\text { 25. Used since } \\
\text { onset of disease }\end{array}$ \\
\hline \multirow[t]{2}{*}{ Bioelectronics therapies } & Magnetic field therapy & & & \\
\hline & Magnet therapy & & & \\
\hline \multirow[t]{8}{*}{ Mind-body medicine } & Dahnhak gymnastics & & & \\
\hline & Yoga & & & \\
\hline & Meditation & & & \\
\hline & Prayer house & & & \\
\hline & Hypnosis & & & \\
\hline & Tai chi & & & \\
\hline & Biofeedback & & & \\
\hline & Relaxation therapy & & & \\
\hline \multirow{3}{*}{$\begin{array}{l}\text { Pharmacological and Biological } \\
\text { therapies }\end{array}$} & Shark gristle & & & \\
\hline & Aroma therapy & & & \\
\hline & Neural therapy & & & \\
\hline \multirow[t]{3}{*}{ Others } & Charcoal powder & & & \\
\hline & Placenta injection & & & \\
\hline & Germanium therapy & & & \\
\hline \multicolumn{5}{|l|}{ Others not mentioned above } \\
\hline & & & & \\
\hline & & & & \\
\hline & & & & \\
\hline
\end{tabular}

\section{* Write your answers to questions 26 and 27 in the table below.}

26. Please enter the types of CAM and the appropriate number in the table below for the degree of effect.
(1) Was very effective
(2) Was effective
(3) Not very effective
(4) Didn't work at all
(5) Disease rather worsened

\begin{tabular}{|l|l|l|l|l|l|l|}
\hline \multirow{2}{*}{ Types of CAM } & \multirow{2}{*}{$\begin{array}{c}\text { 26. Degree } \\
\text { of effect }\end{array}$} & $\begin{array}{c}\text { Lasted less than } \\
1 \text { month }\end{array}$ & $\begin{array}{c}\text { Lasted 1-3 } \\
\text { months }\end{array}$ & $\begin{array}{c}\text { Lasted 3-6 } \\
\text { months }\end{array}$ & $\begin{array}{c}\text { Lasted 6-12 } \\
\text { months }\end{array}$ & $\begin{array}{c}\text { Lasted 12 } \\
\text { months or more }\end{array}$ \\
\hline & & & & & & \\
\hline & & & & & & \\
\hline
\end{tabular}


28. If you have experienced side effects while using complementary and alternative medicine, please list the types and their specific side effects in the table below.

Ex) Diarrhea worsened after taking squalene

\begin{tabular}{|c|c|}
\hline Types of CAM & Side effects \\
\hline Ex) Squalene & Diarrhea \\
\hline & \\
\hline & \\
\hline & \\
\hline & \\
\hline & \\
\hline
\end{tabular}

29. When did you first use complementary and alternative medicine in relation to the onset of Ulcerative colitis or Crohn's disease?

(1) Since the onset of symptoms before diagnosis

(2) Within 1 month of your diagnosis

(3) Within 1 year of your diagnosis

(4) Within 2 years of your diagnosis

(5) After 2 years of your diagnosis (specify when: )

30. Were you symptomatic at the time of using complementary and alternative medicine?
(1) Started to use when symptomatic
(2) Started to use after symptoms improved

31. Did you tell your physician about the use of complementary and alternative medicine?

(1) Yes

(2) No, because my physician will tell me not to use CAM anyway

(3) No, because of the thought that my physician will scold me

(4) No, because I do not think CAM has anything to do with the care of my disease

32. Did you continue conventional treatment when using complementary and alternative medicine?

(1) Discontinued conventional treatment while using CAM

(2) Continued conventional treatment while using CAM

(3) Experienced both the above ( 1 and 2)

* If you answered (3) to question 32, please specify below which CAM were combined with conventional treatment and which CAM were used after discontinuing conventional treatment.

1) type of CAM combined with conventional treatment:

2) type of CAM used after discontinuing conventional treatment:

33. What was the purpose of the use of complementary and alternative medicine after the diagnosis of Ulcerative colitis or Crohn's disease??
(1) To treat the disease
(2) To maintain remission
(3) To improve certain symptoms
(4) For general health rather than treatment of disease
(5) Not necessarily expecting an effect, but at the advice of my family
(6) others (describe specifically: 
34. What were the specific reasons for using complementary and alternative medicine? (You can select multiple answers.)

(1) To enhance the treatment effect in combination with conventional treatment

(2) As CAM is a safe treatment with no side effects

(3) As the therapeutic effect of CAM has been proven

(4) For psychological stability (the feeling of doing something for my disease)

(5) Due to the concern about developing side effects from conventional treatment

(6) Because of previous side effects from conventional treatment

(7) Because conventional treatment was not effective

(8) Because I feel uncertain that conventional treatment will work

(9) Because I have a different point of view about the cause and treatment of disease from my physician

(10) In order to stop the use of steroids

(11) In order to avoid surgery

35. What led you or who introduced you to the use of complementary and alternative medicine? (You can select multiple answers.)

(1) My own opinion

(2) Recommendation by friends or family

(3) Recommendation by other patients

(4) Through information from IBD patient meetings

(5) Through information from the media (newspaper, broadcast, magazines)

(6) Through information from the internet

(7) Recommendation from a pharmacist

(8) Recommendation from a physician

(9) Others (describe specifically: )

36. How much did you spend on complementary and alternative medicine in the last 12 months?

( ) won

37. Is the cost of complementary and alternative medicine appropriate?
(1) It is a burden
(2) It is affordable

38. What was the total cost of conventional treatment for Ulcerative colitis or Crohn's disease (including the cost of clinic visits, tests/procedures, hospitalization, surgery, and prescription drugs) over the past 12 months?

( ) won

39. What is your opinion in terms of the effectiveness of conventional treatment and complementary and alternative medicine?

(1) Conventional treatment is more effective than CAM

(2) CAM is more effective than conventional treatment

(3) Conventional and CAM have similar effects

(4) I am not sure

40. What is your opinion in terms of the side effects of conventional treatment and complementary and alternative medicine?

(1) Conventional treatment has more side effects than CAM

(2) CAM has more side effects than conventional treatment

(3) Conventional treatment and CAM have degree of side effects

(4) I am not sure 
41. What is your opinion in terms of the cost of conventional treatment and complementary and alternative medicine?

(1) Conventional treatment is more expensive than CAM

(2) CAM is more expensive than conventional treatment

(3) Both are similar in terms of cost

42. What is your opinion in terms of the reliability of conventional treatment and complementary and alternative medicine?

(1) I trust conventional treatment more than CAM

(2) I trust CAM more than conventional treatment

(3) Both are similar in terms of reliability

43. Are you willing to use complementary and alternative medicine in the future?

(1) I have never used it before, and I do not intend to use it in the future

(2) I have not used it yet, but I am thinking about using it in the future

(3) I have used it but I do not intend to use it in the future

(4) I have used it and I think I will use the same type in the future

(5) I have used it and I am thinking about using a different type in the future

44. If you have never used complementary and alternative medicine, why? (Only answer if you have never used CAM.) (You can select multiple answers.)

(1) Because conventional treatment is effective

(2) For fear that CAM may adversely affect conventional treatment

(3) Because my physician did not recommend CAM (or recommended against CAM)

(4) Because I do not know about CAM

(5) Because I do not have confidence in the effects of CAM

(6) Because CAM has no scientific evidence

(7) Because I am concerned of developing side effects from CAM

(8) Because of the cost of CAM

(9) Because CAM is not accessible and is not easy to find

\section{*Answer questions 44 and 45, only if you have been seen by an oriental doctor (naturopath) for Ulcerative colitis or Crohn's disease.}

45. What was the oriental doctor's view on the treatment of Ulcerative colitis or Crohn's disease?

(1) The disease can be treated with oriental medicine

(2) Oriental medicine my improve symptoms, but cannot treat the disease

(3) The disease cannot be treated with oriental medicine; therefore see a physician for appropriate conventional treatment

(4) Others (describe specifically:

46. What was the oriental doctor's view on the use of conventional treatment for Ulcerative colitis or Crohn's disease??

(1) I was told to stop conventional treatment while taking oriental medicine

(2) I was told to continue taking conventional treatment while taking oriental medicine

(3) Others (describe specifically; 